\title{
CONSTITUIÇÃO DE SINAIS DOS MODOS E PONTOS DE ARTICULAÇÃO DA LÍNGUA PORTUGUESA, EM LIBRAS \\ $* * *$
}

\section{CONSTITUTION OF SIGNS OF THE MODES AND POINTS OF ARTICULATION OF THE PORTUGUESE LANGUAGE, IN POUNDS}

\author{
Alessandra Figueiredo Kraus Passos \\ Wellington Pedrosa Quintino ${ }^{2}$ \\ Luciano Ferreira da Silva
}

Recebimento do texto: $12 / 04 / 2018$

Data de aceite: $15 / 05 / 2018$

RESUMO: O presente trabalho propõe a criação de sinais, em Libras, referentes a termos da fonética articulatória, relacionados aos modos e pontos de articulação, específicos da Língua Portuguesa - LP, elaborados em conjunto com um acadêmico surdo durante a disciplina de Fonética e Fonologia do curso de Letras, da Universidade do Estado de Mato Grosso - UNEMAT. A criação desses novos sinais teve como objetivo proporcionar à comunidade surda, por meio desses sinais, uma melhor compreensão do alfabeto fonético internacional, durante as aulas dessa disciplina. Para tanto, verificamos inicialmente se esses sinais já existiam no Novo Deit-Libras: Dicionário Enciclopédico Ilustrado Trilíngue da Língua de Sinais Brasileira - Libras ou na bibliografia específica dessa área apresentadas nos cursos de Letras Libras ou Letras, no Brasil. Para constituição desses sinais, nos reunimos com os acadêmicos surdos do curso de letras que de alguma forma foram os protagonistas nesse proposição de novos sinais, com o auxílio do site http://www.fonologia.org e orientação do professor da disciplina, explicamos/interpretamos os conceitos básicos da fonética articulatória, a partir de vídeos, que representavam os modos e os pontos de articulação da LP. Os resultados apontaram para a constatação de que, o sujeito surdo, quando tem o contato com sua língua (Libras), no ambiente de ensino, facilita o processo de aprendizagem de uma segunda língua, independente do conteúdo abordado.

PALAVRAS-CHAVE: Libras, criação de sinais, fonética da Língua portuguesa.

ABSTRACT: This paper proposes the creation of signs, in Libras, for terms of articulatory Phonetics, related to the places of articulation, concerning Portuguese Language specific-LP, produced in conjunction with a deaf scholar during the discipline of phonetics and phonology of the Language Course of the State University of of Mato Grosso-UNEMAT. The creation of those new signals aimed to provide the deaf community, through those signs, a better understanding of the International Phonetic Alphabet, during the lessons of that discipline. To do so we have initially analyzed if those signals already existed in the new Lounge-a Trilingual Illustrated encyclopedic dictionary: Libras of Brazilian sign language-Pounds or in specific bibliography this area presented in the courses of letters or Letters, in Brazil. For the Constitution of those signals, we have discussed with the deaf student who, somehow, was the protagonists of the proposition of those new signs. Also with the help of the http://www.fonologia.org site and the orientation of the teacher of the discipline, we have explained/interpreted the basics concepts of articulatory Phonetics, through videos, which represented the articulation of the Portuguese sounds. The results pointed to the fact that, when deaf student have contact with his/her own Language (Libras), in the teaching environment, it facilitates the process of learning a of second language, regardless of the content discussed.

KEYWORDS: Libras, new signs, phonetics of the Portuguese language

\footnotetext{
${ }^{1}$ Mestre e doutoranda pelo Programa de Pós-Graduação em Linguística da Universidade do Estado de Mato Grosso/UNEMAT. Email: andale_passos@hotmail.com

${ }^{2}$ Doutor e professor da área de Linguística do curso de Licenciatura em Letras e do Programa de Pós-Graduação em Linguística da Universidade do Estado de Mato Grosso/UNEMAT. Email: xav@ terra.com.br

${ }^{3}$ Graduando do curso de Licenciatura em Letras pela Universidade do Estado de Mato Grosso/UNEMAT.
}

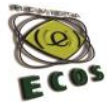




\section{Iniciando um diálogo}

As Línguas de sinais-LSs, utilizadas por comunidades surdas, nem sempre foram respeitadas e somente a partir da década de 1960, que pesquisas sobre as LSs começaram a ser mais difundidas dentro dos estudos linguísticos. Os estudos realizados por Quadros e Karnopp (2004), também confirmam isso. Segundo estes autores os estudos linguísticos das LSs tiveram início com o trabalho precursor de William Stokoe, seguido posteriormente por outros estudiosos, que também tentaram demonstrar que os gestos usados pelos surdos são, na verdade, uma língua sinalizada.

Estudos realizados pela FENEIS (S/D) revelam que, a partir dos resultados positivos do Congresso Mundial de surdos, ocorrido em Paris no ano de 1971, para que as LSs fossem novamente valorizadas, iniciaram-se as discussões a respeito do bilinguismo. Nos registros da FENEIS constam que, no Brasil, essa discussão teve início na década de 1980, com os estudos realizados pelas pesquisadoras Lucinda Ferreira Brito e Eulália Fernandes, sobre a educação dos surdos no Brasil.

As pesquisas dessas professoras seguiram o padrão internacional de abreviação das LSs. A primeira nomeação dada a Libras foi Língua de Sinais Brasileira dos Centros Urbanos - LSCB e posteriormente, a partir de votação, em uma reunião realizada na Federação Nacional de Educação e Integração dos Surdos - FENEIS, no mês de outubro de 1993, para decidirem entre os nomes LSCB ou Libras, foi acordado que para a nomeação da Língua usada pela comunidade surda, seria a segunda opção. A partir de então, Lucinda Ferreira Brito passou a empregar a abreviação Libras, criada pela própria comunidade surda.

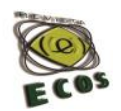


Goldfeld (1997 apud MOURA, 2000) afirma que a Libras, teve, em consequência da chegada de $\mathrm{Huet}^{4}$, influência da Língua de sinais francesa, que posteriormente foi combinando com os sinais já utilizados pelos surdos brasileiros. Provavelmente, a partir dessa combinação e com a criação de outros novos sinais, a Libras foi se estabelecendo.

Embora a educação dos surdos e a Libras estivesse aparentemente progredindo, aqui no Brasil, a luta pelo direito à educação especializada e à liberdade de usar sua própria língua, só começou a ter grandes mudanças depois que comunidades brasileiras de pessoas surdas se organizaram e lutaram por esse direito. Conseguiram, no ano de 2002, a promulgação da lei 10.436/2002 (BRASIL, 2002) e também, no mesmo ano, a lei 10.098/2002 (BRASIL, 2002), que tratam respectivamente dos direitos que os surdos passaram a ter, de serem cidadãos brasileiros. Estas leis favorecem o exercício da cidadania entre aqueles das comunidades surdas. Não obstante os direitos concedidos, continuaram a lutar pela sanção dessas leis.

Em 2005, quando Luiz Inácio Lula da Silva era Presidente da República, a lei 10.436/2002 (BRASIL, 2002) foi regulamentada pelo decreto 5.626/2005 (BRASIL, 2005). A partir deste decreto, tornou-se obrigatória a inclusão da disciplina (Libras) nos cursos de formação de professores, tanto para o magistério como para o ensino superior (Letras, Pedagogia, Educação Especial), como também na área da saúde (Fonoaudiologia).

\footnotetext{
${ }^{4}$ Professor surdo que era sucessor do método de ensino do Abade L Epée (ROCHA, 2010).
} 
Em 2010, é oficializada/regulamentada a lei Federal 12.319/2010 que fortalece o reconhecimento da Libras como segunda língua oficial ${ }^{5}$ do país, o reconhecimento do profissional intérprete, em sala de aula, repartições públicas e demais ambientes que for necessário, como também a promulgação da lei 13.146/2015, que segundo Moraes (2017), na elaboração desses Estatuto, parece ter ocorrido uma negociação entre cultura ouvinte e cultura surda. Pois, em alguns momentos a lei apresenta a surdez como deficiência e outros produz o sentido de respeito às reivindicações da comunidade surda e sua cultura. As nuanças desse processo, ainda, têm sido árduas para as instituições de ensino, pois, são poucos os profissionais interessados em aprender com afinco essa nova segunda língua oficial do país.

Conhecer o percurso histórico da constituição da Libras é compreender todo um processo formador da afirmação cultural, difundida por uma comunidade que sempre lutou pelo direito de exercer sua cidadania brasileira, com os mesmos direitos que todo cidadão ouvinte tem. Todavia, por ser, a Libras, uma LS que ainda está em construção, apresenta lacunas ao se tratar de sinais específicos, como é o caso dos sinais propostos nessa pesquisa. Por não haver sinais apropriados para os termos fonéticos relativos aos modos e pontos de articulação da LP, as aulas da disciplina fonética e fonologia da LP, no curso de licenciatura em Letras, na Universidade do Estado de Mato Grosso/UNEMAT, tornaram-se

\footnotetext{
${ }^{5}$ Por ser a segunda língua reconhecida oficialmente, em todo território brasileiro, a Libras não pode ser considerada como uma língua co-oficial (língua oficial de um território específica de um país), mas como a segunda língua oficial do país, Brasil.
} 
complexas para os alunos surdos. Devido a isso, houve a necessidade de constituição de sinais específicos para esses termos, para melhor compreensão do conteúdo abordado, em sala de aula.

\section{Estrutura gramatical da Libras}

A Libras, assim como qualquer outra Língua, possibilita à criança constituir sua língua materna ao mesmo tempo em que por ela é constituída. (SILVA, 2011 p. 81), sua estrutura gramatical possui todas as características morfológicas, fonológicas, semânticas, pragmáticas e sintáticas das línguas orais. Para Brito (S/D)

A LIBRAS é dotada de uma gramática constituída a partir de elementos constitutivos das palavras ou itens lexicais e de um léxico (o conjunto das palavras da língua) que se estruturam a partir de mecanismos morfológicos, sintáticos e semânticos que apresentam especificidade, mas seguem também princípios básicos gerais (BRITO, S/D, p.4).

É uma língua viva e autônoma, reconhecida pela lingüística (SILVA et al, 2007). No entanto, existe uma significante diferença entre as LSs e LOs, que consiste no modo/canal de percepção e produção das informações linguísticas. Nas LOs, as informações linguísticas são percebidas pela audição e produzidas pelo aparelho fonador, enquanto, nas LSs as informações linguísticas são percebidas pelos olhos e produzidas, mais precisamente, pelas mãos.

A Libras é uma língua de modalidade espaço-visual, articulada espacialmente pelos sujeitos que a utilizam e a relação entre significado e significante é visual. 
Embora exista um grande elevado de sinais icônicos (beber, árvore, casa, avião...), é importante destacar que essa característica não é exclusivamente das línguas de sinais (GESSER, 2009, p. 23). Essas formas icônicas, segundo Martelotta (2011), apresentam características que se assemelham ao objeto ao qual se refere, em outras palavras, a iconicidade é a propriedade de se apresentar semelhante que o ícone tem com o objeto representado.

As pesquisas realizadas sobre a estrutura da LS do Brasil iniciaram-se a partir da década de 1980. De acordo com Silva (2012), essas pesquisas diversificaram-se entre estudo estruturalista, aquisição, histórica, formação de léxico, como também os instrumentos linguísticos: dicionários e proposta de uma gramática.

Com bases em pesquisas realizadas por William Stokoe, Ferreira (2010) afirma que a estrutura linguística da Libras também é formada por parâmetros fonológicos, considerando três, os mais importantes: a configuração da(s) mão(s) (doravante $\mathbf{C M}$ ), o ponto de articulação (doravante PA) e o movimento (doravante M). Observemos na imagem abaixo os parâmetros fonológicos da Libras, sinalizando o sinal "certo".
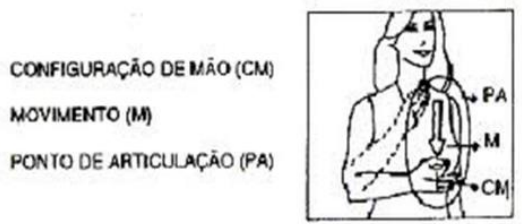

Parâmetros de sinal em Libras.

Fonte: Ferreira (2010, p. 24). 
Ferreira (2010) reafirma que a CM são as diversas formas que as mãos assumem quando estão realizando os sinais. Tais configurações se formulam, a partir das 46 configurações de mão apresentadas pela estudiosa. A cada configuração é possível acrescentar o movimento, ponto de articulação, a expressão não-manual e a posição da (s) mão (s). Vejamos as configurações de mãos propostas por Ferreira (2010):

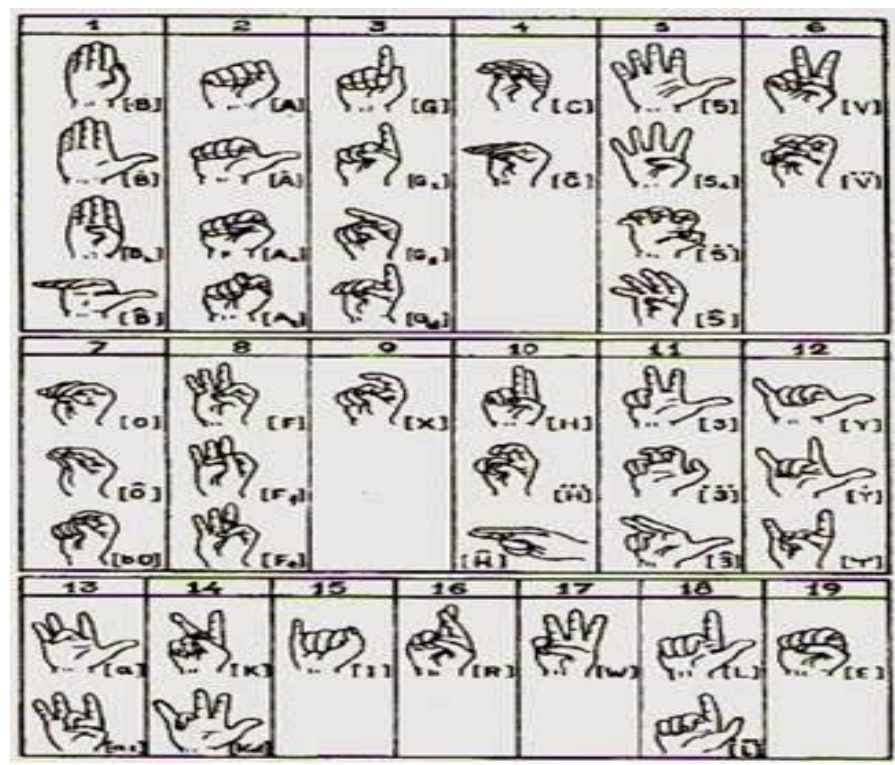

Configurações de mãos da Libras.

Fonte: Ferreira (2010, p. 220).

De acordo com Oliveira (2015), há controvérsias, em relação ao número exato de configurações de mãos usadas pela comunidade surda brasileira. Dentre elas temos o que foi proposto por Lira e Souza (2005) que propuseram $73 \mathrm{CMs}$; Nobre (2011), com a criação de um sistema de buscas do software IDSinais; Faria-do-Nascimento (2009) que também

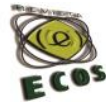


desenvolveu uma proposta de ordenação de configurações de mãos, como também, Castro $^{6}(2011)$ que registrou $61 \mathrm{CMs}$. As CMs postuladas por Castro foram bem difundidas nos materiais comercializados pela LSB Vídeos. Contudo, não era possível encontrar referência para o inventário de CMs documentado pelo autor. Somente, em 2006, com a publicação do trabalho didático Curso de Libras, em parceria com Quadros, que isso foi possível. Vejamos o quadro de CMs proposto por Castro:

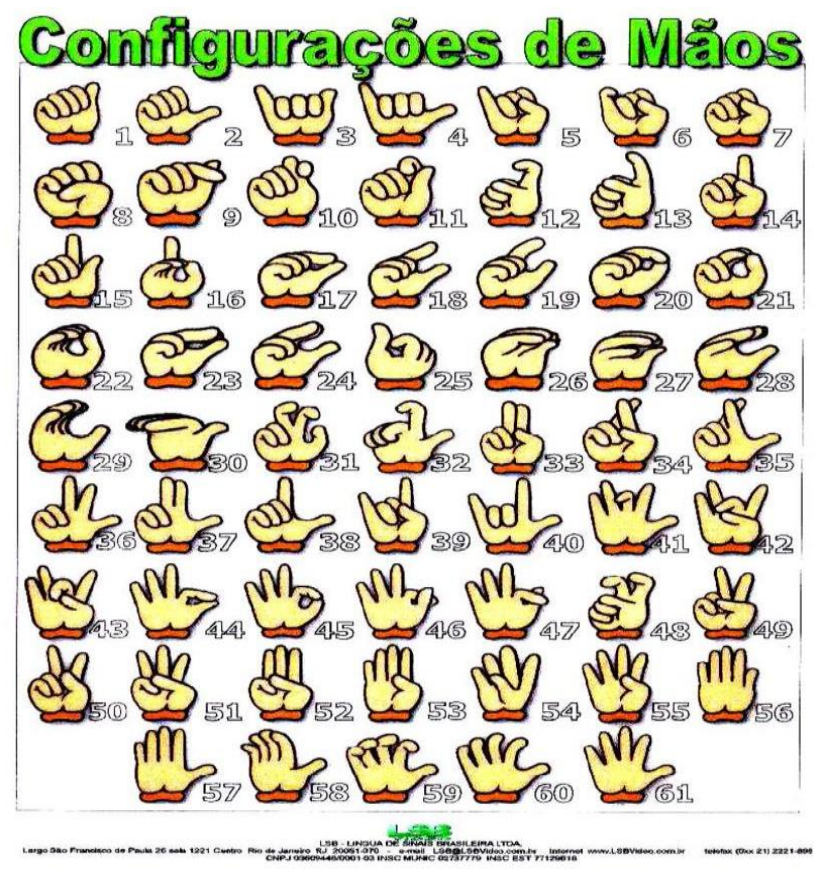

61 Configurações de Mãos da Libras.

Fonte: http://charles-libras.blogspot.com.br/2014/10/configuracoes-de-mao.html.

\footnotetext{
${ }^{6}$ Nelson Pimenta de Castro é surdo e professor titular do Departamento de Educação Básica no INES, Mestre e doutorando do Programa de Pós-Graduação em Estudos da Tradução da UFSC.
}

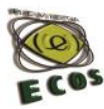


Para Ferreira (2010), o parâmetro M é compreendido como sendo complexo, pois abarca uma ampla rede de configurações e direções, que apresentam traços fonológicos, ou seja, distintivos de significado, envolvendo desde os movimentos do pulso, das mãos, antebraços, os movimentos internos das mãos, os movimentos direcionados no espaço, que podem acontecer de modo unidirecional, bidirecional e multidirecional, até a descrição de sua velocidade, tensão e qualidade, como também possibilidade de perceber a frequência/repetições do movimento no momento da realização do sinal.

Quadros e Karnopp (2004) sugerem um quadro para mostrar as categorias do parâmetro M, postulado por Brito (1990), como segue:

\begin{tabular}{|c|c|}
\hline \multicolumn{2}{|c|}{ Categorias do parâmetro movimento da Libras (Ferreira, 2010) } \\
\hline \multicolumn{2}{|r|}{ TIPO } \\
\hline Contorno & Retilíneo; helicoidal; circular; semicircular; sinuoso; angular e pontual. \\
\hline Interação & Alternado; de aproximação; de separação; de inserção e cruzado. \\
\hline Contato & $\begin{array}{l}\text { De ligação; de agarrar; de deslizamento; de toque; de esfregar; de riscar; de } \\
\text { escovar ou pincelar. }\end{array}$ \\
\hline Torcedura do pulso & Rotação e com refreamento. \\
\hline Dobramento do pulso & Para cima e para baixo. \\
\hline Interno das mãos & Abertura; fechamento; curvamento e dobramento (simultâneo/gradativo). \\
\hline \multicolumn{2}{|r|}{ DIRECIONALIDADE } \\
\hline Unidirecional & $\begin{array}{l}\text { Para cima; para baixo; para a direita; para esquerda; para dentro; para fora; } \\
\text { para o centro; para a lateral inferior esquerda; para a lateral inferior direita; } \\
\text { para a lateral superior esquerda; para a lateral superior direita e para } \\
\text { específico ponto referencial. }\end{array}$ \\
\hline Bidirecional & $\begin{array}{l}\text { Para cima e para baixo; para esquerda e para direita; para dentro e para fora } \\
\text { e para laterais opostas - superior direita e inferior esquerda. }\end{array}$ \\
\hline \multicolumn{2}{|l|}{ Não-direcional } \\
\hline \multicolumn{2}{|r|}{ MANEIRA } \\
\hline Qualidade, tensão e velocidade & Contínuo, de retenção e refreado. \\
\hline \multicolumn{2}{|r|}{ FREQUÊNCIA } \\
\hline Repetição & Simples e repetido. \\
\hline
\end{tabular}


O terceiro parâmetro, considerado um dos mais importantes na estrutura gramatical da Libras por Ferreira (2010), PA ou Locação (doravante L), é definido pela autora como "o espaço em frente ao corpo ou região do próprio corpo, onde os sinais são articulados” (FERREIRA, 2010, p. 37). É o espaço/área de enunciação em que estão reunidos todos os pontos possíveis para realização do sinal. Projetado sobre os consecutivos segmentos:

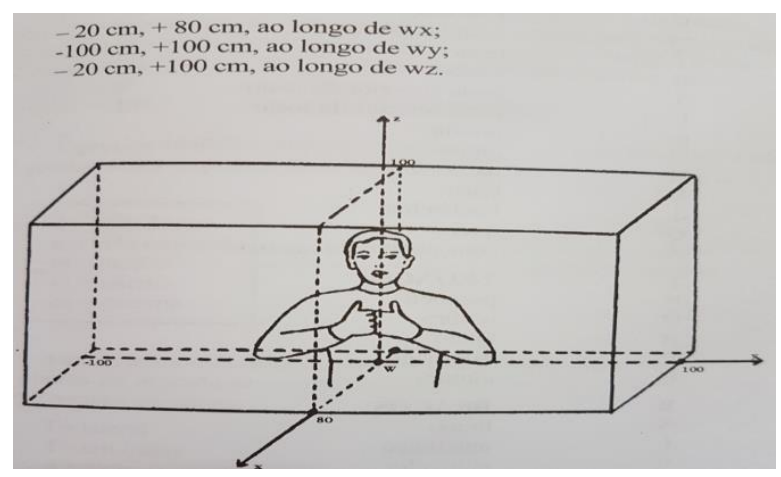

Espaço de realização dos sinais. Fonte: Ferreira (2010, p.215)

Os pontos de articulação são delimitados dentro do referido espaço e divididos em quatro principais regiões, porém é necessário o emprego de mais alguns outros termos, pois também são distintivos de significado.

\begin{tabular}{|l|l|}
\hline \multicolumn{2}{|c|}{ Quadro de Pontos de Articulação proposto por Ferreira (2010, p. 216) } \\
\hline \multicolumn{1}{|c|}{ CABEÇA } & Dedo mínimo \\
\hline Topo da cabeça & Anular \\
& \\
\hline Testa & Dedo médio \\
& \\
\hline
\end{tabular}




\begin{tabular}{|c|c|}
\hline Rosto & Indicador \\
\hline Parte superior do rosto & Polegar \\
\hline Parte inferior do rosto & Interstícios entre os dedos \\
\hline Orelha & Interstício entre o polegar e o indicador \\
\hline Olhos & Interstício entre os dedos indicador e médio \\
\hline Nariz & Interstício entre os dedos médio e anular \\
\hline Boca & Interstício entre os dedos anular e mínimo \\
\hline Bochechas & PERNA \\
\hline Queixo & ESPAÇO NEUTRO \\
\hline Zona abaixo do queixo & Adjetivos $^{7}$ que localizam precisamente o PA \\
\hline TRONCO & Lado direito \\
\hline Pescoço & Lado esquerdo \\
\hline Ombro & Medial \\
\hline Busto & Interna \\
\hline
\end{tabular}

${ }^{7}$ O que Ferreira (2010) define como adjetivo, entendemos como conjunto de traços que podem ser distintivo de significado. 


\begin{tabular}{|c|c|}
\hline Estômago & Externa \\
\hline Cintura & Descrição de translação horizontal $^{8}$ do PA \\
\hline BRAÇOS & Lateral \\
\hline Braço & Em frente \\
\hline Antebraço & Atrás \\
\hline Cotovelo & Descrição dos demais PA \\
\hline Pulso & Imediatamente próximo \\
\hline MÃO & Distância média \\
\hline Palma & Distante \\
\hline Costas da mão & Em contato \\
\hline Lado do indicador & Contato inicial \\
\hline Lado do dedo mínimo & Contato medial \\
\hline Dedos & Contato final \\
\hline Ponta dos dedos & Cruzamento \\
\hline
\end{tabular}

${ }^{8}$ Embora Ferreira (2010) trate apenas de translação horizontal há inúmeros casos em que o traço manifesto evolve uma translação vertical. 


\begin{tabular}{|l|l|}
\hline Nós dos dedos (junção entre os dedos e a mão) & \\
\hline Nós dos dedos (primeira junta dos dedos) & \\
\hline
\end{tabular}

Ainda sobre a estrutura interna da Libras, de acordo Quadros e Karnopp (2004), posterior aos estudos de Stokoe, Battison (1974) e outros pesquisadores propuseram mais dois parâmetros, com base na existência de pares mínimos, em sinais que apresentam mudança de significado, com, apenas, a troca de um desses parâmetros, a saber, orientação das mãos e expressão não manual.

A Orientação das Mãos (doravante Or) é o parâmetro que tem a função de direcionar a palma da mão no momento da realização do sinal, podendo ser voltada para o corpo, para direita; para esquerda; para cima; para baixo; para frente. Durante a sinalização pode ocorrer mudança de Or da palma da mão.

Já o parâmetro Expressão Não Manual (doravante ENM), são aqueles movimentos/expressões realizadas na face, nos olhos, na cabeça ou no tronco. Como proposto por Ferreira (2010), no quadro a seguir:

\begin{tabular}{|c|l|}
\hline Expressões não-manuais da Libras. Ferreira (2010, p. 240-241) \\
\hline \hline \multirow{5}{*}{ ROSTO } & Parte Superior: \\
& Sobrancelhas franzidas \\
& Olhos arregalados \\
& Lance de olhos \\
& Sobrancelhas levantadas \\
& Parte inferior \\
& Bochechas infladas \\
& Bochechas contraídas \\
& Lábios contraídos e projetados e sobrancelhas franzidas \\
& Correr da língua contra a parte inferior interna da bochecha \\
& Apenas a bochecha direita inflada \\
& Contração do lábio superior \\
\hline
\end{tabular}




\begin{tabular}{|c|l|}
\hline & Franzir do nariz \\
\hline \multirow{2}{*}{ CABEÇA } & $\begin{array}{l}\text { Balanceamento para frente e para trás (sim) } \\
\text { Balanceamento para os lados (não) } \\
\text { Inclinação para frente } \\
\text { Inclinação para o lado } \\
\text { Inclinação para trás }\end{array}$ \\
\hline ROSTO E CABEÇA & $\begin{array}{l}\text { Cabeça projetada a frente, olhos levemente cerrados, sobrancelhas franzidas } \\
\text { (ex.: o que?, quando?, como?, quando?, por que?) } \\
\text { Cabeça projetada para trás, e olhos arregalados (ex.: quem?) }\end{array}$ \\
\hline TRONCO & $\begin{array}{l}\text { Para frente } \\
\text { Para trás } \\
\text { Balanceamento alternado de ombros } \\
\text { Balanceamento simultâneo de ombros } \\
\text { Balanceamento de um único ombro }\end{array}$ \\
\hline
\end{tabular}

Para Brito (S/D), nas línguas orais, o que é designado como itens lexicais/palavras, nas línguas de sinais são reconhecidos como sinais. Assim, os sinais são formados a partir das combinações entre os referidos parâmetros (CM, M, PA, Or. e ENM) dessas línguas. Embora, sejam apenas cinco parâmetros, ao se combinarem, geram um número limitado de sinais, com a função de determinar o sentido/significado entre um sinal e outro, que por sua vez combinados e recombinados formam um número ilimitado de possibilidades diferentes de produção de sentenças.

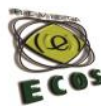




\section{Disciplina de fonética e fonologia das Línguas Orais - LOs}

Saussure é o precursor nos estudos que apresentaram as primeiras diferenças existentes entre fonética e fonologia, ou seja, a fonética não pode ser considerada uma ciência, como é a fonologia, pois a função da fonética é disponibilizar dados para os estudos fonológicos e não o de realizar estudos científicos.

Segundo Roberto (2016), a fonética articulatória disponibiliza dados relacionados à produção dos sons da fala, das diversas formas de realizações dos fonemas, ao passo que a fonologia se atenta em estudar o comportamento desses fonemas, e sua organização interna, sendo do interesse da fonética articulatória, apresentar o fone, todo e qualquer som produzido pelo aparelho fonador humano, enquanto a fonologia tem como objeto de estudo o fonema, representação abstrata, mais profunda, da forma de base que diz respeito a função do segmento dentro do sistema.

De acordo com Silva (2015), a fonologia é uma área da linguística que estuda o componente sonoro das línguas naturais, pelo viés organizacional. É responsável em determinar a distribuição dos sons e os possíveis contrastes entre eles, como também caracteriza "a boa-formação das sílabas e dos aspectos suprassegmentais como, por exemplo, o tom e o acento" (SILVA, 2015, p. 110).

Há, nos cursos de letras das universidades públicas ou privadas no Brasil uma disciplina que trata dos sons do português. No curso de Licenciatura em Letras, na Universidade Estatual do Estado de Mato Grosso, faz jus ao seu nome Língua portuguesa 2: fonética e fonologia. $\mathrm{O}$ uso de termos complexos, condizentes com as suas especificidades, são 
necessários para compreensão do conteúdo, em especial os modos e pontos de articulação do aparelho fonador humano. No entanto, na turma, onde foi realizada essa pesquisa, havia alunos surdos e devido a isso, as aulas se tornaram, muitas vezes, desconfortantes para esses alunos e sua interprete, uma vez que não havia sinais, em Libras, para vários desses termos.

Em virtude deste impasse, algumas medidas foram tomadas pela interprete, com o propósito de melhorar a compreensão do conteúdo. Com apoio dos alunos surdos a interprete combinava alguns sinais, usava a datilologia e fazia indicação de palavras no quadro fonético. Todos esses recursos não foram o suficiente para que esses alunos compreendessem como os modos e pontos de articulação funcionam dentro do aparelho fonador humano. A necessidade de constituir sinais apropriados, para esses termos, tornou-se extremamente necessário, pois não faziam parte do léxico mental dos alunos surdos e, naquele momento, nem dos alunos ouvintes.

\section{Constituição dos sinais}

Os surdos existem desde a Antiguidade. Enquanto humano, está sempre fadado a comunicar-se. Partindo desse pressuposto é natural a existência de uma língua utilizada por esse grupo de pessoas, que infelizmente ainda não é totalmente reconhecida socialmente, enquanto unidade linguística.

Segundo Skliar (1999), os surdos são pessoas que se comunicam, relacionam-se, interagem e se posicionam a partir de experiências visuais. Essas experiências abarcam todos os tipos de representações, significações 
e/ou produções, podendo ser tanto no campo linguístico, cultural, artístico, intelectual, estético, ético, cognitivo, dentre outros.

Para Strobel (2013), a cultura surda possibilita o sujeito surdo a compreender o mundo e, também, a modificá-lo de acordo com suas necessidades de torná-lo acessível e habitável. Isto significa que abrange a língua, as ideias, as crenças, os costumes e os hábitos do povo surdo (STROBEL, 2013, p. 29).

De acordo com Gesser (2009) as pessoas surdas conseguem, com e através da língua de sinais, assegurar a construção de conhecimento de mundo e o fortalecimento de sua cultura. Entretanto, é equivocado o pensamento de que o surdo compartilhe apenas de uma cultura, pois todos estão sujeitos a serem perpassados por outras culturas que estão em contato.

Assim como as demais línguas em todo mundo, o vocabulário da Libras está em constante desenvolvimento. Nas línguas orais acrescentamse novas palavras, enquanto nas LSs incluem-se novos sinais. Isso acontece porque podemos falar diversas coisas de diversas formas a partir das regras de cada língua (GESSER, 2009, p. 27). Como diria Sacks (2010, p. 105) A língua emerge - biologicamente - de baixo, da necessidade irreprimível que tem o indivíduo humano de pensar e se comunicar. Partindo desse pressuposto a nossa pesquisa corresponde com a necessidade de compreensão de alguns alunos surdos, mais precisamente, de graduandos de uma disciplina que trata da fonética e fonologia do português, no curso de licenciatura em Letras da Universidade do Estado de Mato Grosso, pois, em virtude da falta de sinais, específicos dessas áreas, houve a necessidade de se constituir novos sinais em Libras. 
A constituição de novos sinais em Libras, para os modos e pontos de articulação da LP, ocorreram no período de estágio docente de uma integrante dessa pesquisa, na turma do $2^{\circ}$ semestre de Letras, sob a supervisão do professor Dr Wellington Pedrosa Quintino, responsável pela disciplina Língua portuguesa 2: fonética e fonologia.

O estágio realizado na Pós-Graduação é uma etapa importante para os mestrandos, é nesse momento que a experiência docente, no curso superior, concretiza-se e possibilita experimentar situações até então desconhecidas, que a teoria não permitiu/permite alcançar.

Nas primeiras semanas de aula, o professor explicou o que é sílaba, como é organizada a representação da estrutura silábica e sobre as respectivas posições das consoantes e vogais. Apresentou, também, os tipos de sílabas existentes na língua portuguesa, realizou transcrições fonéticas lexicais e consequentemente fez as representações das estruturas silábicas, pretendendo assim, que os alunos se desprendessem da escrita e se atentassem ao som da fala, para compreenderem como esses sons são produzidos e representados pelos símbolos fonéticos e, assim percebessem a diferença entre o som e a escrita.

Por se tratar de sons, as aulas ficaram um pouco complexas para os acadêmicos surdos, como já mencionamos anteriormente. Com auxílio e apoio da interprete foi possível, nos primeiros momentos, relacionar o conteúdo com as experiências visuais desses alunos, de forma que conseguiram perceber o funcionamento das articulações fonéticas e as representações das estruturas silábicas. Contudo, não conseguiram visualizar alguns traços que eram distintivos de significado, como o traço

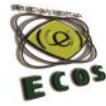


[voz], quando o professor pronunciava. Devido a isso, foi necessário ir em busca de materiais que pudessem auxiliá-los na aprendizagem desses traços.

Em virtude da modalidade da língua de sinais, ser visual, eles precisariam de algo visual para compreender as diferenças entre fones e fonemas. Dessa forma foi apresentado o site, http://www.fonologia.org/fonetica, e mostrado os símbolos fonéticos, como também uma imagem do aparelho fonador disponível no site. Essa imagem representava a articulação interna de cada símbolo fonético selecionado, ou seja, a cada símbolo fonético selecionado a imagem reproduzia-o de forma que era visível como esse som era articulado internamente. Conquanto, foi percebido que havia um outro problema, ninguém, no grupo, sabia os sinais, em Libras, para os modos e pontos de articulação, a interprete precisava ficar usando a datilologia para interpretar. Para que não ficasse cansativo, no momento da explicação, os modos e pontos de articulação foram apontados diretamente no quadro fonético.

Este método não perdurou por muito tempo, pois quando foi necessário realizar o ditado, como atividade, isso ficou mais complexo, pois a todo o momento precisava apontar os símbolos no quadro. Devido a isso, foi proposto uma busca por esses sinais em Libras, pois não era do nosso interesse criar sinais de termos já existentes. A constituição desses sinais só ocorreria caso não existissem.

A busca por sinais específicos, relacionados aos modos e pontos de articulação da língua portuguesa, foi realizada em sites de Instituições que oferecem os cursos de Licenciatura em Letras e Letras Libras, como também, procurou-se saber se já havia registros no Novo Deit-Libras: 
Dicionário Enciclopédico Ilustrado Trilíngue da Língua de Sinais Brasileira - Libras. Entretanto, não houve êxito, não existiam esses sinais. Devido a isso, tornou-se necessário organizar um momento para elaboração da constituição dos sinais. Como os alunos surdos já haviam compreendido o funcionamento interno do aparelho fonador humano, foi necessário, apenas, mostrar e explicar o sentido/função das palavras relacionadas. A partir da compreensão do graduando surdo, integrante dessa pesquisa, os sinais foram constituídos e desenhados pelo mesmo. Vejamos quais são os modos e pontos de articulação da LP:

\begin{tabular}{|l|l|}
\hline \multicolumn{2}{|c|}{ MODO DE ARTICULAÇÃO DA LP } \\
\hline Nasal & $\mathrm{m}, \mathrm{n}, \mathrm{n}, \mathrm{n}$ \\
\hline Oclusiva & surdas: $\mathrm{p}, \mathrm{t}, \mathrm{k}$ e sonoras: $\mathrm{b}, \mathrm{d}, \mathrm{g}$ \\
\hline Fricativa & surdas: $\mathrm{f}, \mathrm{s}, \mathrm{f}, \mathrm{x}$ e sonoras: $\mathrm{v}, \mathrm{z}, \mathrm{3}, \mathrm{r}$ \\
\hline Aproximante/Glide & $\omega, \mathrm{J}$ \\
\hline Tape & $\uparrow, \mathrm{r}$ \\
\hline Africada & $\mathrm{t}, \mathrm{d}$ \\
\hline Aproximante lateral/líquida & $1, \kappa$ \\
\hline
\end{tabular}

\begin{tabular}{|l|l|}
\hline \multicolumn{2}{|c|}{ PONTO DE ARTICULAÇ̃̃O DA LP } \\
\hline Bilabial & $\mathrm{m}, \mathrm{p} \mathrm{b}$ \\
\hline Labio-Dental & $\mathrm{f} \mathrm{v}$ \\
\hline Dental & $\mathrm{n}, \mathrm{t} \mathrm{d}, 1$ \\
\hline Alveolar & $\mathrm{s} \mathrm{z}, \Gamma, \mathrm{f}$ d 3 \\
\hline Pós-Alveolar & $\mathrm{f}_{3}$ \\
\hline Retroflexo & $\mathrm{n}, \mathrm{r}$ \\
\hline Palatal & $\mathrm{n}, K, \mathrm{j}$ \\
\hline Velar & $\mathrm{kg}, \mathrm{x}_{\mathrm{r}}, \omega$ \\
\hline
\end{tabular}

Não existem nomeações, em LP, para os símbolos fonéticos, o que existe são símbolos que representam os sons da fala. Pensando nisso foi constituído sinais, em Libras, para os modos e pontos de articulação. Vejamos: 
ISSN: 2316-3933

Online

REVISTA ECOS

Programa de Pós-graduação em Estudos Literários/ UNEMAT

Programa de Pós-graduação em Linguística/ UNEMAT

Centro de Estudos e Pesquisas em Literatura

Centro de Estudos e Pesquisas em Linguagem

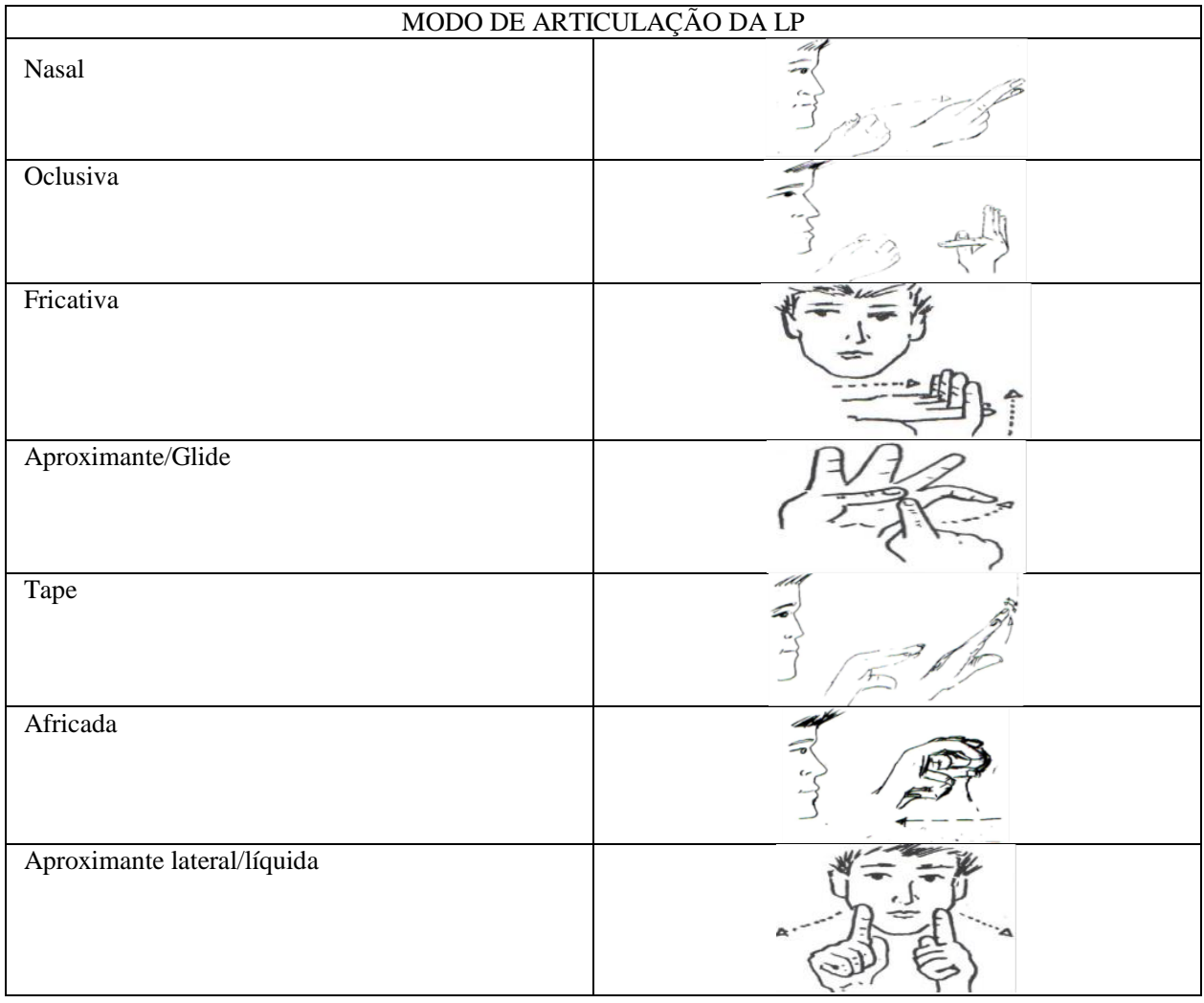

\begin{tabular}{|l|l|}
\hline \multicolumn{2}{|c|}{ PONTO DE ARTICULAÇÃO DA LP } \\
\hline Bilabial & \\
\hline Labio-Dental & \\
\hline Dental & \\
\hline Plveolar & \\
\hline
\end{tabular}


ISSN: 2316-3933

Online

Programa de Pós-graduação em Estudos Literários/ UNEMAT

Programa de Pós-graduação em Linguística/ UNEMAT

Centro de Estudos e Pesquisas em Literatura

Centro de Estudos e Pesquisas em Linguagem

\begin{tabular}{|l|l|}
\hline Retroflexo & \\
\hline Palatal & \\
\hline Velar & \\
& \\
\hline
\end{tabular}

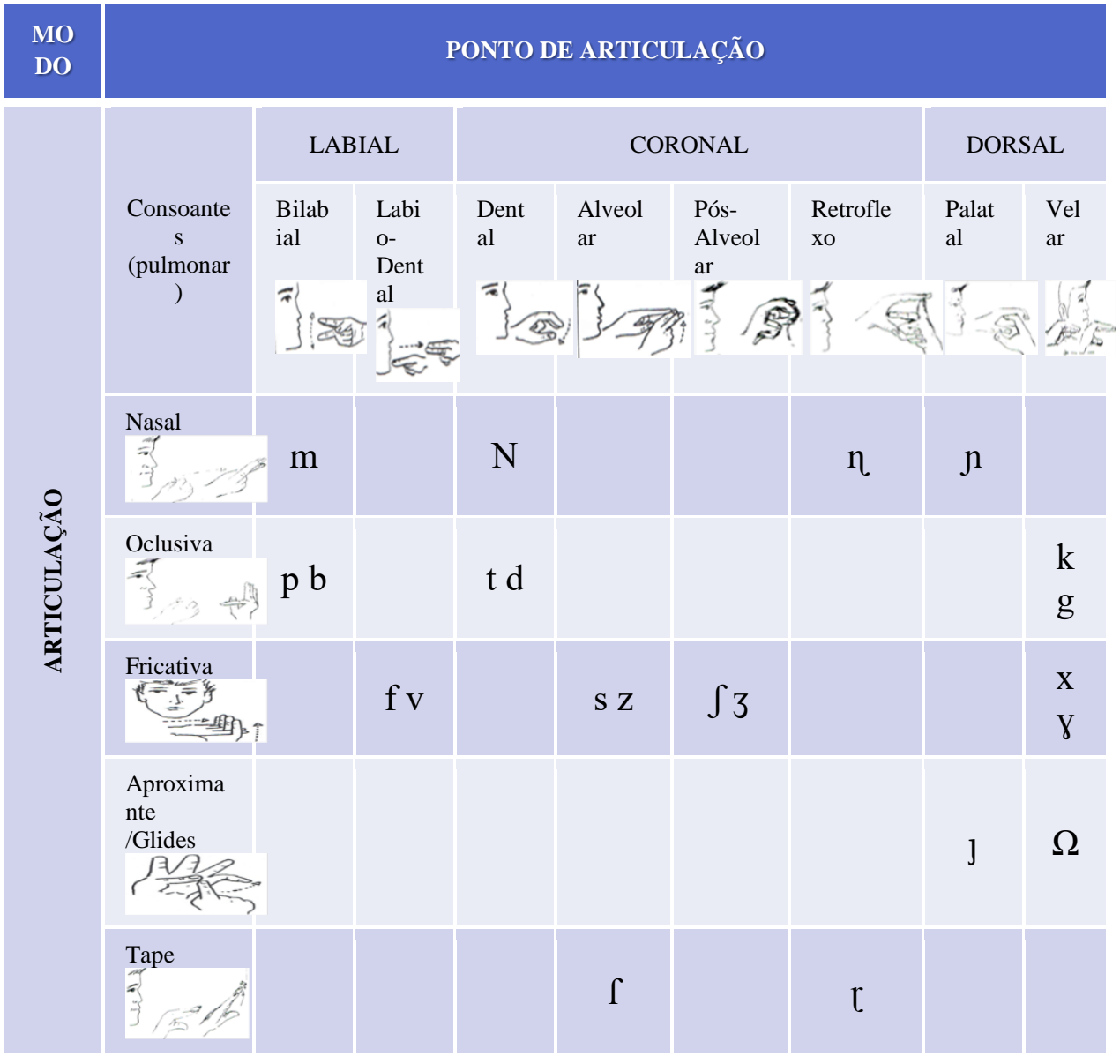




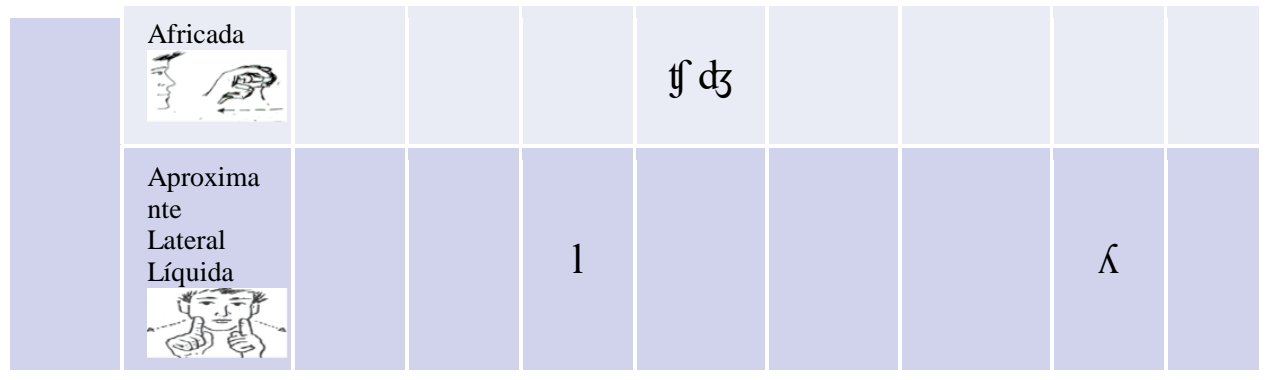

Os resultados apontaram para a constatação de que, a pessoa surda, quando tem o contato com sua língua (Libras), no ambiente de ensino, facilita o processo de aprendizagem de uma segunda língua, independente do conteúdo abordado, pois esses alunos acompanharam a turma, mas com um diferencial, conseguiam assimilar, com mais propriedade os pontos e modos de articulação dos sons assim como noção de sílaba e a estrutura silábica, em comparação com alguns alunos ouvintes da mesma turma. Isso provavelmente deve ter ocorrido pelo motivo dessa representação mais abstrata não depender da audição, mas da visão.

\section{Considerações finais}

Neste estudo foi possível perceber a necessidade de novos sinais, em Libras, nas áreas de fonética e fonologia das línguas orais, em especial, da LP. Em virtude do ingresso de alunos surdos em cursos que têm, em sua matriz curricular, estudos relacionados a essas áreas.

Em particular, essa pesquisa proporcionou, aos acadêmicos surdos do curso de Licenciatura em Letras da UNEMAT, uma melhor compreensão do funcionamento do aparelho fonador humano e como os

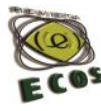


modos e os pontos de articulação funcionam no interior do trato oral. Isso se deve ao sentido produzido na língua natural desses alunos. Almejamos poder corroborar com a constitucionalização da Libras, difundindo sinais que poderão contribuir com novos estudos.

\section{Referências}

BRASIL. Lei $\mathbf{n}^{\mathbf{0}}$. 10.436 de 24 de abril de 2002. Dispõe sobre a Língua Brasileira de Sinais - Libras e dá outras providências. Disponível em: <http://www.planalto.gov.br/ccivil_03/leis/2002/110436.htm>. Acesso em: 17/09/2014.

BRITO, Lucinda Ferreira. Gramatica de LIBRAS. Disponível em: http://pt.scribd.com/doc/22653284/A-Gramatica-de-Libras-LUCINDAFERREIRA-BRITO. Acesso em: 02 out. 2013.

CAPOVILLA, Fernando C.; RAPHAEL, Walkiria D.; LUZ, Renato D. Como usar este dicionário enciclopédico ilustrado trilíngue. In: CAPOVILLA, Fernando César; RAPHAEL, Walkiria Duarte. Dicionário enciclopédico ilustrado trilíngue da língua de sinais brasileira. 3. ed. Ilustrações de Silvana Marques. São Paulo: Editora da Universidade de São Paulo: Imprensa Oficial do Estado, v. I: sinais de A a L e v. 11: sinais de M a Z. 2013.

Configuração de mãos. Disponível em: Fonte: http://charleslibras.blogspot.com.br/2014/10/configuracoes-de-mao.html. Acesso dia 17/08/2017. 
FENESIS. História da Educação do surdo no Brasil. Disponível em: http://www.feneis.com.br/page/noticias_detalhe.asp?categ=1\&cod=623. Acesso em: 02/09/2013.

FERREIRA, Lucinda. Por uma gramática de Língua de Sinais. Rio de Janeiro, RJ: Tempo Brasileiro, 2010.

Fonética e Fonologia. Disponível em: http://www.fonologia.org. Acesso dia 03/06/2017.

GESSER, Audrei. LIBRAS?: que língua é essa?: crenças e preconceitos em torno da língua de sinais e da realidade surda. São Paulo: Parábola Editorial, 2009.

MARTELOTTA, Mário Eduardo et al. Manual de linguística. São PauloSP: Contexto, 2011.

MOURA, M. C. de. O surdo: caminhos para uma nova identidade. Rio de Janeiro: Revinter, 2000.

OLIVEIRA, Janine Soares de. Análise descritiva da estrutura querológica de unidades terminológicas do glossário Letras-Libras. 2015, 425 p. Tese (Doutorado em Estudos da Tradução) - Programa de Pós - Graduação em Estudos da Tradução, Universidade Federal de Santa Catarina $\quad$, Florianópolis, 2015.

QUADROS, Ronice Müller de; KARNOPP, Lodenir Becker. Língua de sinais brasileira: Estudos linguísticos. Porto Alegre, RS: Artmed, 2004.

ROBERTO, Tania Mikaela Garcia. Fonologia, Fonética e ensino: guia introdutório. 1. ed. São Paulo, SP: Parábola Editorial, 2016.

SACKS, Oliver. Vendo vozes: uma viagem ao mundo dos surdos. Tradução Laura Teixeira Motta. São Paulo, SP: Companhia das Letras, 2010. 
SAUSSURE, Ferdinand de. Curso de linguística geral. $27^{\mathrm{a}}$ ed. Org. por Ch. Bally e Sechehaye, com a colaboração de A Reidlinger. Trad. Antônio Chelini, José Paulo Paes e Izidoro Blikstein. São Paulo, SP: Cultrix, 2006. SILVA, Carmem Luci da Costa. Os movimentos enunciativos da criança na linguagem. Revista da ABRALIN, v. Eletrônico, n. Especial, p. 77-94. $2^{\mathrm{a}}$ parte 2011.

SILVA, Fábio Irineu da; REIS, Flaviane; et al. Aprendendo língua brasileira de sinais como segunda língua. Santa Catarina: NEPES, 2007. SILVA, Nilce Maria da. Instrumento linguísticos de Língua Brasileira de Sinais: constituição e formulação. 2012, 272 p. Tese (Doutorado em Linguística) - Instituto de Estudos de Linguagem, Universidade Estadual de Campinas, Campinas, 2012.

SILVA, Thaïs Cristofáro. Dicionário de Fonética e Fonologia. 1 ed. São Paulo, SP: Contexto, 2015.

SKLIAR, Carlos. Atualidade da educação bilíngüe para surdos: processos e projetos pedagógicos. Vol.1. Porto Alegre: Mediação. 1999. STROBEL, Karin Lilian. As imagens do outro sobre a cultura surda. 3 ed. Florianópolis: Ed. da UFSC, 2013. 